\title{
First report of grapevine Pinot gris virus in wild grapevines (Vitis coignetiae) in Japan
}

\author{
Junya Abe ${ }^{1} \cdot$ Tomoyuki Nabeshima $^{2}$ D
}

Received: 31 January 2021 / Accepted: 26 February 2021 / Published online: 1 March 2021

(c) Società Italiana di Patologia Vegetale (S.I.Pa.V.) 2021

Grapevine Pinot gris virus (GPGV) was first identified in Italy from symptomatic Vitis vinifera 'Pinot Gris' (Giampetruzzi et al. 2012). Since then, GPGV has been detected in most grapevine-growing regions worldwide (Hily et al. 2020). In September 2020, leaf samples were collected from three symptomatic (mosaic or chlorotic mottling of the leaves) and 12 asymptomatic wild $V$. coignetiae growing naturally in Hokkaido, Japan. Total RNA was extracted and pooled into a single sample. This pooled RNA was sequenced using DNBSEQ-G400 (MGI TECH), and 38,507,344 paired reads were obtained. The reads were trimmed and assembled using CLCgenomic WorkBentch (Qiagen). Then the contigs were mapped to the $V$. vinifera genome (GenBank accession No. GCA_000003745.2), and the unmapped contigs were collected. Among these, we found two contigs covering nearly the full-length GPGV genome; one was 7,070 bp long with $78.1 \%$ nucleotide sequence identity with GPGVFEM01 (KU312039.1) and the other was 7,169 bp long with $80.4 \%$ nucleotide sequence identity to SRR5332103GPGV2 (BK011083.1). To confirm the infection of GPGV, we designed a primer pair of GPGV_CPfull_F1 (5'-ATC TGGCTGTGCTGAAAATA-3') and GPGV_CPfull_R1 (5'-ACTACATACTAAATGCACTCTCC-3') to amplify the full-length coat protein (CP) gene by RT-PCR. Amplicons of the expected size $(657 \mathrm{bp})$ were obtained in 5 out of 15 plants. Direct sequencing of amplicons showed three types of nucleotide sequences that were highly homologous to known GPGV sequences with $86 \%-87 \%$ nucleotide identity $(87.5 \%$ to MN458457.1) and $90 \%-98 \%$ amino acid identity (97.9\% to AGV76026.1). Sequences determined in this study were submitted to GenBank under accession numbers LC601811 to LC601812 (contigs) and LC601601 to LC601603 (viral CP region). Sequences corresponding to LC601601-LC601603 were recovered from two, one, and two infected plants, respectively. To our knowledge, this study is the first to report the detection of GPGV in Japan.

\section{Declarations}

Conflicts of interest The authors declared no conflict of interest.

Research involving human participants and/or animals The authors declare that no human participants and animals were involved in this study.

\section{References}

Giampetruzzi A, Roumi V, Roberto R, Malossini U, Yoshikawa N, La Notte P, Terlizzi F, Credi R, Saldarelli P (2012) A new grapevine virus discovered by deep sequencing of virus- and viroidderived small RNAs in cv. Pinot gris. Virus Res 163:262-268. https://doi.org/10.1016/j.virusres.2011.10.010

Hily JM, Poulicard N, Candresse T, Vigne E, Beuve M, Renault L, Velt A, Spilmont AS, Lemaire O (2020) Datamining, genetic diversity analyses, and phylogeographic reconstructions redefine the worldwide evolutionary history of grapevine Pinot gris virus and grapevine berry inner necrosis virus. Phytobiomes J 4:165-177. https://doi.org/10.1094/PBIOMES-10-19-0061-R

Publisher's Note Springer Nature remains neutral with regard to jurisdictional claims in published maps and institutional affiliations.

Tomoyuki Nabeshima

nabeshima@tds1.tr.yamagata-u.ac.jp

1 Smart Agriculture Division, JFE Engineering Corporation, 2-1, Suehiro-cho, Tsurumi-ku, Yokohama 230-8611, Japan

2 Department of Agriculture, Yamagata University, 1-23, Wakaba-machi, Tsuruoka 997-8555, Japan 